\title{
Diagnosis of chronic rhinosinusitis: can nasal endoscopy be the new gold standard in developing countries?
}

\author{
Sushant Tyagi ${ }^{1}$, Mohit Srivastava ${ }^{1}$, Vandana Singh ${ }^{2}$
}

\author{
${ }^{1}$ Department of ENT, SIMS, Hapur, UP, India \\ ${ }^{2}$ LLRM, Meerut, UP, India
}

Received: 16 December 2015

Accepted: 27 December 2015

\section{*Correspondence:}

Dr. Mohit Srivastava,

E-mail: mohit141180@gmail.com

Copyright: (C) the author(s), publisher and licensee Medip Academy. This is an open-access article distributed under the terms of the Creative Commons Attribution Non-Commercial License, which permits unrestricted non-commercial use, distribution, and reproduction in any medium, provided the original work is properly cited.

\section{ABSTRACT}

Background: Objective of the study was to study the role of diagnostic value of nasal endoscopy in diseases involving nasal cavity and paranasal sinuses particularly chronic rhinosinusitis in developing countries.

Methods: A total of 200 Patients with clinical evidence of sinonasal diseases were evaluated. All patients were subjected to thorough ENT examination with special emphasis on anterior and posterior rhinoscopy. Nasal Endoscopy was done using Hopkins rod endoscopes $\left(0^{\circ}, 30^{\circ}, 45^{\circ}, 70^{\circ}\right.$ and $\left.90^{\circ}\right)$ - diameter $2.7 \mathrm{~mm} / 4 \mathrm{~mm}$, length $18 \mathrm{~cm}$ after administering a spray puff of Xylocaine with adrenaline (10 drops of adrenaline to $2 \mathrm{ml}$ of Xylocaine). Computed tomography of paranasal sinuses was done in 100 patients whose symptoms, examination and clinical picture were sufficient to warrant the procedure.

Results: The most common anatomical variations detected on nasal endoscopy were deviated nasal septum (83.5\%) followed by paradoxical middle turbinate (42.5), and concha bullosa $(26.5 \%)$. Accessory middle turbinate was seen in 7 out of 200 cases $(3.5 \%)$. The most common pathological abnormality detected on nasal endoscopy was mucopus in middle meatus (69\%) and next were hypertrophied (45 and 35\% inferior and middle turbinate respectively) and congested turbinates $(44.5 \%)$, followed by polypoidal changes $(28 \%)$ and oedematous/congested uncinate process $(27.5 \%)$.

Conclusion: Diagnostic nasal endoscopy can prove to be a better diagnostic modality compared to CT scan when conditions like middle meatal secretions, condition of mucosa, polyps are looked for. It can detect early polypoidal and other pathological changes missed on CT which can aid in early diagnosis and medical management of sinonasal diseases thereby preventing patient from unnecessary surgical exposure. Also being easily available and cost effective, patients can be spared from unnecessary cost and radiation exposure by performing diagnostic nasal endoscopy prior to CT.

Keywords: Chronic rhinosinusitis, Nasal endoscopy, CT-PNS

\section{INTRODUCTION}

Nasal endoscopy is an excellent example where diagnostic and therapeutic advances can make disease process more accessible. Rhinology has undergone revolutionary changes in the last 20 years. ${ }^{1}$ Hirschmann performed the first attempts at nasal and sinus endoscopy in 1901 using a modified cystoscope. ${ }^{2}$ In 1925, Maltz used the term sinuscopy and described techniques for endoscopically examining the maxillary sinuses via both inferior meatal and canine fossa routes. ${ }^{3}$ He wisely noted the diagnostic capabilities of endoscopy and the limitations of relying solely on radiographic information. It was not until the middle of the twentieth century, when Professor HH Hopkins developed the rod optic telescope, that endoscopy of the upper airway made the next major advancement. 
Nasal Endoscopy is a minimally invasive, diagnostic medical procedure and currently the preferred initial method of evaluating medical problems such as nasal stuffiness and obstruction, sinusitis, nasal polyps, nasal tumours, and epistaxis. ${ }^{5}$ Endoscopy remains a mainstay for evaluating nasal blockage and its causes. This technique can be used more effectively than simple anterior rhinoscopic examination to diagnose anatomical variations that may cause nasal congestion, as well as to observe signs of crusting and pus indicative of on going infection.

The objective was to study the role of diagnostic value of nasal endoscopy in diseases involving nasal cavity and paranasal sinuses particularly chronic rhinosinusitis in developing countries.

\section{METHODS}

A total of 200 Patients with clinical evidence of sinonasal diseases were evaluated with Nasal endoscopy. Out of these 100 underwent computed tomographic evaluation. The cases for the study were selected from the patients attending the ENT OPD with clinical evidence of chronic or recurring acute rhinosinusitis for more than three months non responsive to appropriate medical therapy. all the patients in the study group were subjected to detailed history of wide spectrum of presenting symptoms viz. facial pain, headache, nasal discharge (whether it is watery, mucoid, purulent or blood mixed), nasal obstruction (its duration, whether it is continuous or intermittent and whether it is associated with any external nasal deformity). The presence of other symptoms like postnasal discharge, sneezing, acute/chronic/serous otitis media were also noted in full details. The complete personal, past and family history were also elicited in addition with past medical/surgical history to know about the any chronic use of antihistaminic, steroid sprays and other medications in the past.

All patients were subjected to thorough ENT examination with special emphasis on anterior and posterior rhinoscopy. Nasal Endoscopy was done using Hopkins rod endoscopes $\left(0^{\circ}, 30^{\circ}, 45^{\circ}, 70^{\circ}\right.$ and $\left.90^{\circ}\right)$ - diameter $2.7 \mathrm{~mm} / 4 \mathrm{~mm}$, length $18 \mathrm{~cm}$ after administering a spray puff of Xylocaine with adrenaline (10 drops of adrenaline to $2 \mathrm{ml}$ of Xylocaine). Computed Tomography of Paranasal sinuses was done in 100 patients whose symptoms, examination and clinical picture were sufficient to warrant the procedure. Coronal planes were selected, as it is the plane in which anatomy and pathology are examined almost identical to view of endoscopist and it best displays both the ostiomeatal changes and relationship of brain to ethmoid sinus. The data from data collection forms were tabulated in a Microsoft Excel® spreadsheet. Data were then exported to SPSS, version 20.0 for statistical analysis. The level of agreement between CT and Endoscopy findings was determined by calculating kappa statistics; considering kappa coefficient: $\leq 0$ poor, $0.01-0.20$ slight, $0.21-0.40$ fair, 0.41-0.60 moderate, $0.61-0.80$ substantial, and 0.81-1 almost perfect. Chi-square and Student's t tests were used for statistical analyses. $\mathrm{P}$ value $<0.05$ was considered statistically significant.

\section{RESULTS}

In our study the various cases in $\%$ of the groups in descending order are; group 21-30 (31\%), group 10-20 (26\%), group 31-40 (20\%), group 41-50 (14.5\%) and group above 50 (8.5\%). (Figure 'a') Out of 200 patients; 106 were male and 94 were female. (Figure 2) M: F ratio $=1.12: 1$.

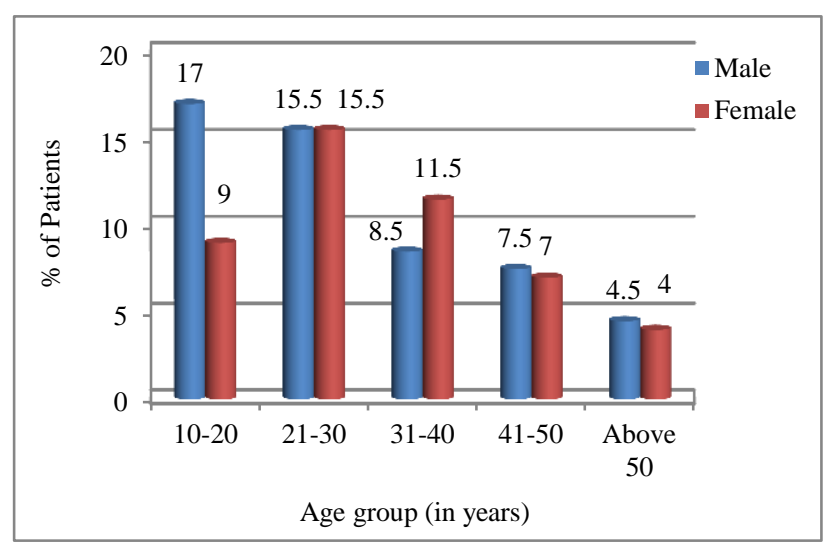

Figure 1: Age (sex-wise) incidence of sinonasal diseases.

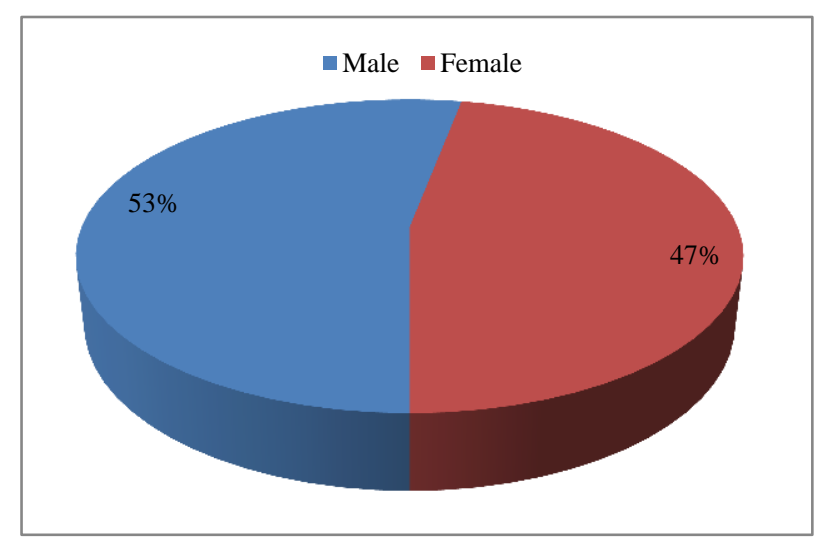

Figure 2: Sex distribution.

$27 \%$ patients had prolonged history of 2-5 years and $22.5 \%$ had symptoms persisting for more than five years; while a small percentage of patients (2.5\%) had symptoms lasting 3 months. The most common symptom was nasal obstruction ( $89 \%$ ) followed by nasal discharge (81\%), PND $(40.5 \%)$, headache (34\%), ear discharge/ heaviness $(25.5 \%)$ and nasal mass $(20 \%)$.

The most common anatomical variations detected on nasal endoscopy was deviated nasal septum (83.5\%) followed by paradoxical middle turbinate (42.5), and concha bullosa (26.5\%). Accessory middle turbinate was 
seen in 7 out of 200 cases $(3.5 \%)$. The most common pathological abnormality detected on nasal endoscopy was mucopus in middle meatus $(69 \%)$ and next were hypertrophied (45 and $35 \%$ inferior and middle turbinate respectively) and congested turbinates $(44.5 \%)$, followed by polypoidal changes $(28 \%)$ and oedematous/congested uncinate process $(27.5 \%)$.

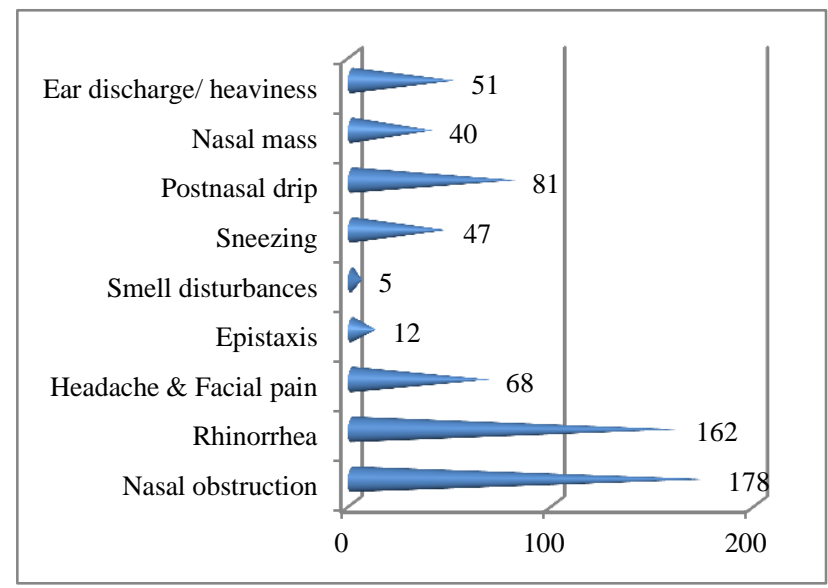

Figure 3: Symptoms distribution of the patients.

The findings detected on computed tomography were deviated nasal septum in $66.25 \%$, concha bullosa in $42.5 \%$ and paradoxical middle turbinate in $16.25 \%$ patients. The findings detected on computed tomography were inferior turbinate hypertrophy in $48.75 \%$, middle turbinate hypertrophy in $38.75 \%$, and polyp in $31.25 \%$ patients. Amongst sinuses, maxillary sinus was the most common sinus to be involved $(42.67 \%)$, followed by anterior and posterior ethmoid air cells (71.25 and
$46.25 \%$ respectively), frontal sinus $(32.5 \%)$ and sphenoid sinus $(21.25 \%)$.

The most diagnosis was deviated nasal septum (45\%) and next was chronic rhinosinusitis (43\%), nasal polyposis $(26.5 \%)$. Out of 200 cases there were two cases each of Allergic fungal rhinosinusitis and nasopharyngeal carcinoma and one case each of inverted papilloma and U/L Proptosis (Rt) of rhinogenic origin.

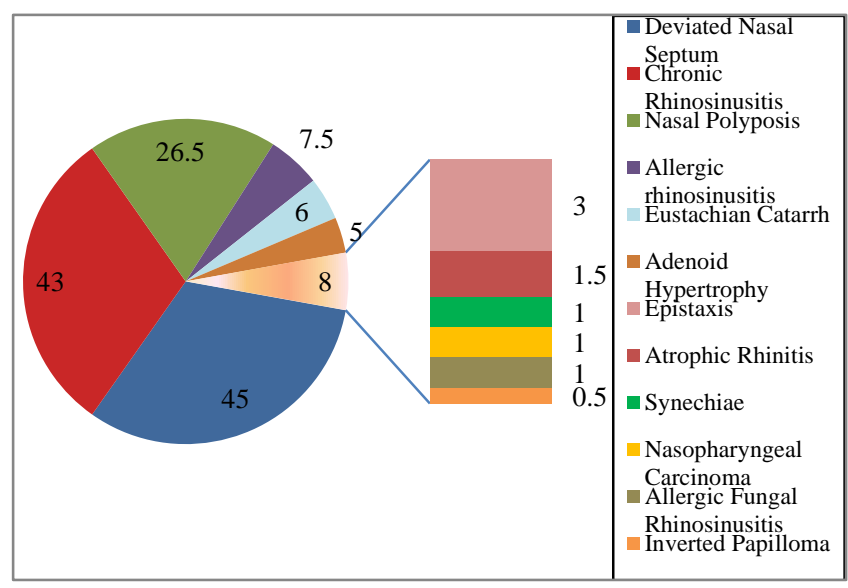

Figure 4: Diagnosis of the patients in the study.

As revealed by the above table, the level of agreement between diagnostic nasal endoscopy and CT is almost perfect for deviated nasal septum, turbinate hypertrophy, concha bullosa, medially bent uncinate process and polyp; substantial for paradoxical middle turbinate and slight for bulla ethmoidalis. This observation was found to be statistically significant, with $\mathrm{p}<0.05$.

Table 1: Level of agreement between diagnostic nasal endoscopy and computed tomography in patients with sinonasal diseases.

\begin{tabular}{|c|c|c|c|c|c|c|}
\hline \multirow{2}{*}{ Finding } & \multicolumn{2}{|c|}{ Endoscopy Positive } & \multicolumn{2}{|c|}{ Endoscopy Negative } & \multirow{2}{*}{ к } & \multirow{2}{*}{$\mathbf{p}$} \\
\hline & CT positive & CT negative & CT positive & CT negative & & \\
\hline Deviated Nasal Septum & 61 & 4 & 2 & 33 & 0.826 & $<0.05$ \\
\hline Inferior Turbinate Hypertrophy & 48 & 2 & 1 & 49 & 0.914 & $<0.05$ \\
\hline Middle Turbinate Hypertrophy & 40 & 6 & 1 & 53 & 0.842 & $<0.05$ \\
\hline Concha Bullosa & 41 & 0 & 3 & 56 & 0.886 & $<0.05$ \\
\hline Paradoxical Middle Turbinate & 23 & 7 & 0 & 70 & 0.776 & $<0.05$ \\
\hline Uncinate Process Medially Bent & 18 & 2 & 1 & 79 & 0.846 & $<0.05$ \\
\hline Bulla Ethmoidalis & 40 & 8 & 27 & 25 & 0.246 & $<0.05$ \\
\hline Polyp & 34 & 5 & 1 & 60 & 0.886 & $<0.05$ \\
\hline
\end{tabular}

\section{DISCUSSION}

Sinonasal endoscopy is an essential part of the rhinologic examination performed by otolaryngologists in the evaluation of sinonasal disease. The use of the endoscopes has been popularised with the advent of endoscopic sinus surgery. This popularity, along with the high incidence of chronic rhinosinusitis, has resulted in the increasing frequency of use of endoscopes for both diagnostic and therapeutic reasons. ${ }^{6}$ Diagnostic endoscopic nasal evaluations has been widely described. Huerter JV described the basic technique to begin with 
the anterior rhinoscopy for membrane evaluation. ${ }^{7}$ Careful history and endoscopic nasal examination suggest the need for CT for evaluation of the paranasal sinuses hidden from endoscopic view. The candidates for CT as described by Rice are patients without endoscopic abnormalities but with a positive history, or patients undergoing preoperative evaluation for endoscopic surgery. ${ }^{8}$

In the present study we included 200 patients with $53 \%$ male and majority being in the age group of 21-30 years. Most of them had a prolonged history of sinonasal symptoms and lasted for at least a year or two. The most common clinical presentation in our study was nasal obstruction $(89 \%)$ followed by rhinorrhea, post nasal drip and headache. The most common diagnosis on nasal endoscopy was chronic rhinosinusitis and deviated nasal septum (43 and 45\% respectively) followed by nasal polyposis $(26.5 \%)$. Hughes et al also showed polyposis and chronic infective rhinosinusitis to be the most common diagnosis in their study. ${ }^{9}$ We found $7.5 \%$ patients with signs of allergic rhinitis on nasal endoscopy of which $66.67 \%$ had history of asthma or allergy similar to the results of the study conducted by De Cleyn et al. ${ }^{10}$

The principal role of computed tomography scanning in rhinosinusitis is as a planning investigation for patients requiring functional endoscopic sinus surgery. The preoperative scan is used to highlight any potential surgical hazards, and to delineate the extent of disease reducing unnecessary intervention in disease-free areas. White et al, ${ }^{11}$ believed that it is inappropriate for CT to be used purely as a diagnostic investigation for chronic rhinosinusitis. They insisted that nasoendoscopy be performed prior to scanning to reduce unnecessary CT demand.

However according to Kasapoglu et al computed tomography and nasal endoscopy are supplementary to each other in preoperative evaluation of patients with chronic sinusitis. ${ }^{12}$ Anatomic variations such as medially deviated uncinate processus, concha bullosa, and paradoxical middle turbinate located at the middle meatus can easily be identified with nasal endoscopy but information on their anatomic details and expansion of the sinus disease cannot be obtained. On the other hand, CT scanning allows describing anatomic details and expansion of the sinus diseases.

Nasal endoscopy is a useful tool to detect the origin of the soft tissue pathology and to plan the surgery. According to Indispensability of nasal endoscopy in preoperative planning and diagnosis is clear. A good endoscopic examination will also reduce unnecessary scanning procedures. The results of endoscopy and CT comparison in our study indicated that although for most of the findings, there was almost perfect to substantial level of agreement between the results of the two methods, some discrepancies existed in some of the patients. 5 patients had normal CT imaging based on the radiologist's report, while they demonstrated nasal polyps during endoscopic evaluation. Also, one case of Allergic fungal rhinosinusitis was falsely diagnosed as sinonasal polyposis on CT. Moreover, CT missed 4 cases of deviated nasal septum. Similar findings were reported by Zojaji et al in his study, in which patients who had negative CT scans, showed endoscopic exams with nasal polyposis and septum deviation. ${ }^{13}$

\section{CONCLUSION}

Diagnostic nasal endoscopy can prove to be a better diagnostic modality compared to CT scan when conditions like middle meatal secretions, condition of mucosa, polyps are looked for. It can detect early polypoidal and other pathological changes missed on CT which can aid in early diagnosis and medical management of sinonasal diseases thereby preventing patient from unnecessary surgical exposure.Also being easily available and cost effective, patients can be spared from unnecessary cost and radiation exposure by performing diagnostic nasal endoscopy prior to CT. Also, in pathological benign nasal mass histopathological is essential for its diagnosis where diagnostic nasal endoscopy can prove useful in taking precise biopsy, to know the exact pathology and to plan further management.

\section{Funding: No funding sources \\ Conflict of interest: None declared}

Ethical approval: The study was approved by the Institutional Ethics Committee

\section{REFERENCES}

1. Orlandi RR, Marple BF. Developing, Regulating, and Ethically Evaluating New Technologies in Otolaryngology-Head and Neck Surgery. Otolaryngol Clin N Am. 2009;42:747-52.

2. Draf W. Endoscopy of the paranasal sinuses, New York:Springer-Verlag Inc, 1983 (quoted bySchlosser RJ, Kennedy DW. Nasal Endoscopy. In: Gleeson M, editor. Scott-Brown's Otorhinolaryngology, Head and Neck Surgery. Edward Arnold Publishers 1td. 2008;2:1344-54.

3. Maltz M. New instrument: the sinuscope. Laryngoscope.1925; -35: 805-11 (quoted bySchlosser RJ, Kennedy DW. Nasal Endoscopy. In: Gleeson M, editor. Scott-Brown's Otorhinolaryngology, Head and Neck Surgery. Edward Arnold Publishers ltd. 2008;2:1344-54.

4. Messerklinger W. Endoscopy of the nose. Baltimore: Urban Et Schwarzenberg. (quoted bySchlosser RJ, Kennedy DW. Nasal Endoscopy. In: Gleeson M, editor. Scott-Brown's Otorhinolaryngology, Head and Neck Surgery. Edward Arnold Publishers ltd. 2008;2:1344-54.

5. Soudry E, Nayak JV. Nasal Endoscopy. American Rhinologic Society: revised. 2011;9. 
6. Durr DG, Wright ED, Gall RM. Sinonasal Endoscopy Reporting Format: Emphasis on Chronic Rhinosinusitis. The Journal of Otolaryngology, 2005;34(3):183-8.

7. Huerter JV. Functional Endoscopic Sinus Surgery and Allergy. Oto laryngol Clin North Am. 1992;25(1):231-7.

8. Huerter JV. Functional Endoscopic Sinus Surgery and Allergy. Oto laryngol Clin North Am. 1992;25(1):231-7.

9. Hughes RGM, Jones NS. The role of nasal endoscopy in outpatient management, Clin. Otolaryngol. 1998;23:224-6.

10. De Cleyn M, Kersschot EA, De Clerek ES. Paranasal sinus pathology and non allergic respiratory tract diseases. Allergy. 1986;41:313-8.

11. White PS, Maclennan AC, Connolly AA. Analysis of CT scanning referrals for chronic rhinosinusitis. J Laryngol Otol. 1996;110(7):641-3.
12. Kasapoglu F, Onart S, Basut O. Preoperative evaluation of Chronic Rhinosinusitis patients by conventional radiographies, computed tomography and nasal endoscopy. Kulak BurunBogazIhtisDerg. 2009;19(4):184-91.

13. Zojaji R. Mirzadeh M, Naghibi S. Comparative Evaluation of Preoperative CT Scan and Intraoperative Endoscopic Sinus Surgery Findings in Patients with Chronic Rhinosinusitis. Iran J Radiol. 2008;5(2):77-82.

Cite this article as: Srivastava M, Tyagi S, Singh V. Diagnosis of chronic rhinosinusitis: can nasal endoscopy be the new gold standard in developing countries? Int J Otorhinolaryngol Head Neck Surg 2016;2:30-4. 